\title{
Business or Fun?: Similarities and Differences between Portuguese and International Wine Bloggers
}

\author{
J. Freitas Santos
}

ISCAP, Porto Polytechnic and NIPE, Minho University, S. Mamede de Infesta, 4465, Portugal

\begin{abstract}
The worldwide emergence of blogs has presented marketers with a new communication channel. Despite the increasing growth of wine blogs little is understood about the practices and motivations of wine bloggers. This exploratory study investigates the similarities and differences of profile, uses and motivations between Portuguese and international wine bloggers. The results show significant differences in rating (rating versus non-rating) and wine samples (acceptance or not). Marginally differences were found in the blogging activity age and motivations. Similarities were found in the frequency of posts, adoption of advertising, statistical tools to measure blog traffic and licence content of the blog.
\end{abstract}

Keywords Wine Blogs, Wine Bloggers, Wine Marketing, Wine Business

\section{Introduction}

The number of Internet users has doubled over the past five years and there are now more than two billion internet users worldwide. According to ITU (2011), by the end of 2010 , around $30 \%$ of the world's population was online (against 12\% in 2003, and 6\% in 2000)[1]. The proportion of households with access to the internet is growing steadily, both in the developing countries (16\% at the end of 2010), and developed countries (66\%). Penetration rates in Europe are well above $50 \%$ (and often more than $80 \%$ ). By the end of 2010 more than two in three people were online and over $80 \%$ of all internet subscribers had broadband connection. Broadband is important as many of the most effective applications and services are only available through a high-speed Internet connection. In 2010, the percentage of Portuguese individuals using internet is $51.1 \%$ and the percentage of households with computer and Internet is 59.5\% and $53.7 \%$, respectively, while the broad band internet subscriptions per 100 inhabitants is 19.4 [1].

One of the most recent developments in the World Wide Web is the so-called social web. The social web is the online place where people with common interests can gather to share thoughts, comments and opinions. It includes: i) social networks such as MySpace, Facebook, LinkedIn; ii) branded web destinations like Amazon, and eBay; iii) enterprise sites such as IBM, Cisco, and Oracle (Weber, 2009)[2]. The social web is an unpaid media created by individuals or enterprises on the web, which have the capacity to change public

* Corresponding author:

jfsantos@iscap.ipp.pt (J. Freitas Santos)

Published online at http://journal.sapub.org/mm

Copyright (C) 2012 Scientific \& Academic Publishing. All Rights Reserved opinion. Some strategies include: i) search engines such as Google, and Yahoo; ii) blogs hosted on Blogger and other blog sites, and micro-blog site Twitter; iii) Topic-specific e-communities involving healthcare, sports, etc.; iv) social networks, such as You Tube (more than 10 billion videos a month), or Flickr (more than 40 million visitors monthly to see photos and videos)[2]. Blogs are websites that allow persons to instantly publish content about a certain subject. Bloggers provide commentary or news on a particular topic, such as wine. A typical blog combines text, images and links to other blogs, webpages, and other media related to its theme. Blogs are dynamic, easily updated and more personal, as readers have the ability to leave comments or questions in an interactive way (Wright, 2006)[3].

Today, there are millions of blogs on the Internet and some hundred thousands are created everyday. A study by Technorati (2008) reported that 900,000 blogs are posted every day and 133 million blog records are indexed in their database since 2002. Most of the bloggers in Europe and Asia are males $(73 \%$ ) while in the United States (US) the percentage is lower $(57 \%)$. The average monthly unique visitor is higher in Asia $(26,000)$, than in Europe $(24,000)$ and the US (18,000)[4]. According to Universal McCann (2008), 346 million people read blogs (60.3\% in US) and 184 million started a blog (24.6\% in US). When writing in the blog $26.6 \%$ of the internauts write on the topic "opinions on products and brands" and the interest is similar when reading a blog (26\%)[5].

The study of blogs and their use for business has received recently strong attention of international researchers (Kozinets et al., 2010; Trusov et al., 2009; Woerndl et al., 2008; Thompson and Sinha, 2008)[6-9]. Blogs possess functional characteristics that can promote and support a variety of business uses. Blogs can be as a public relations tool as one 
of their goals is to build relationships (Menzie and Keyton, 2007)[10] and influence public opinion specifically with regard to buying decisions (Berger, 1987)[11]. Some of these techniques included: online product recommendations (Senecal and Nantel, 2004)[12], product placement (visual, audio or audio-visual) used as a tool to report positive experiences and thoughts about a product or a brand (Karrh et al., 2003)[13]; electronic Word-of-Mouth (eWOM), now viewed as co-produced in consumer groups, communities, or networks (Xia and Bechwati, 2008; Xiaofen and Yiling, 2009; Kozinets et al., 2010)[14-15,6]; consumer communities build around shared themes (products or brands) to expand market exposure and enhance customer relationship (Ives and Watlington, 2005; Jang et al., 2008; Vecchio et al., 2009)[16-18].

Wine bloggers can be seen as a specific virtual community that explicitly center upon wine-related interests. They can be defined as affiliative groups whose online interactions are based upon shared enthusiasm for, and knowledge of wine[6]. These blogs can be used independently by people to say some provocative things about wine (ratings, restaurants, food, etc.) or creating online communities of people interested in share thoughts, activities and reactions about wine. Some of the most popular blogs are commercial that utilize their reach to promote products and business. Alder Yarrow at vinography.com compiled 656 blogs in English, with an additional 163 wine blogs in other languages, including Italian (41), French (37), German (35), Spanish (22), and Portuguese (11) [accessed April 20, 2010].

To the best of our knowledge little empirical effort has been made to identify wine blogging practices and to understand their rationales and motivations. This comparative study focuses on the differences between Portuguese and international wine bloggers and addresses three main questions: who are they?, what are they doing?, why are they blogging on wine?. To answer these questions we examine the practices of Portuguese and international wine bloggers and investigate their profile, uses and motivations.

This research can be useful to managers of wine firms for several reasons: (i) wine blogs can be a rich source of information to better understand consumers and opinion leaders; (ii) wine blogs provide a unique marketing tool to promote wine through Internet; (iii) WOM is an increasingly important technique to influence the conduct of consumer-to-consumer communications; (iv) strategic implications of the existence of different types of both virtual communities and community participation must be consider. The interest of the research could be extended to the wine blog community as some of the implications could help to improve their blogs.

The paper is organized as follows. Section 1 briefly examines empirical evidence on the uses of blogs for marketing purposes. Section 2, discusses theoretical contributions in order to understand the motivations of wine bloggers. Next section refers to the research methodology (sample, data collection and methods). Section 4 is dedicated to the com- parative analysis of the profile, uses and motivations of Portuguese and international bloggers. Finally, conclusions are given by discussing our findings and suggesting some marketing implications for bloggers and managers of wine firms.

\section{Blogs as a Marketing Tool}

The use of blogs for promoting products and brands has been studied since the emergence of the social web. Chevalier and Mayzlin (2006) used book reviews posted by customers at two Internet retail sites (Amazon and Barnes and Nobles) to research how customer WOM affects consumer purchasing behaviour[19]. The results suggest that an improvement in a book's reviews leads to an increase in relative sales at that site and the impact of 1-star reviews is greater than the impact of 5-star reviews. Xia and Bechwati (2008), based on two experiments, show that the level of cognitive personalization developed while reading an online review influences consumers' purchase intentions. In addition, the level of cognitive personalization is a function of the reader's affect intensity, the nature of the product reviewed (experience vs. search) and the content of the review (experiential vs. factual)[14]. Xiaofen and Yiling (2009) explore the consumer attitude and intention towards Internet apparel purchasing, concluding that online WOM and opinion leader comments influence positively consumer's willingness to buy clothes[15].

Using data from online social networking site, Trusov et al. (2009) found that WOM referrals have a very strong impact on new customer acquisition and have a larger and longer-lasting effect than traditional marketing activity[7]. Kozinets et al. (2010) studied a marketing campaign in which mobile phones were seeded with prominent bloggers. The findings indicate that bloggers responded with four types of WOM communication strategies. Evaluation strategies focus on the good and service promoted rather than the market campaign. Embracing strategies offer a bold, self-interested justification for participation in the WOM campaign alongside their open adoption of their dual role as a consumer and marketer. Endorsement strategies disclose the marketing campaign and discuss its potential drawbacks but appeal for communal assistance, support, and understanding. Explanation strategies openly disclose and analyze the marketing campaign, acknowledging its potential conflict while asserting the importance and interests of the community[6].

Senecal and Nantel (2004) investigate consumers' usage of online recommendation sources and their influence on online product choices. They conclude that subjects who consulted product recommendations selected recommended products twice as often as subjects who did not consult recommendations. Further, the source labelled "recommender system", typical of the personalization possibilities offered by online retailing, was more influential than more traditional recommendation sources such as "human experts" 
and "other consumers". The type of product also had a significant influence on the propensity to follow product recommendations[12].

Blogs (corporate or consumer) had also been used in the context of brand communities: as an effective tool to manage the relationships with customers, to enhance brand loyalty or adopt a new product. Vecchio, et al. (2009) examined the social dynamics and dimensions observed inside the Dell bloggers community to conclude that is a hybrid community, larger than it could seem, in which the initiative of the firm through the corporate blog is mixed in a not well-defined space with several other communities founded spontaneously by the users. The authors add that this customer virtual community can provide a large amount of knowledge and relational insights that firms can acquire and use by interacting with the market[18]. Jang et al. (2008) looked into the extent to which brand communities contribute to the creation of brand commitment, and whether these breed more loyal customers. The results show that in the case of consumerinitiated communities the information available, quality of the systems, interaction between the members and the rewarding of the members all play a role in achieving commitment. In the case of company-initiated communities only the last two factors are important[17]. Thompson and Sinha (2008) explore the relationship between brand community membership and new product adoption to conclude that higher levels of participation and longer-term membership in a brand community increase the likelihood that a customer will adopt a new product from that brand. Furthermore, higher participation and longer membership duration reduce the likelihood of adopting a new product from a competing brand[9].

\section{Bloggers' Motivations}

A commonly used framework to understand motivations in computer-mediated communications is the uses and gratifications theory (Blumler and Katz, 1974; Ruggiero, 2000)[20-21]. The theory suggests that media users play an active role in choosing and using the media. Users take an active part in the communication process and are goal oriented in their media use. The authors add that a media user seeks out a media source that best fulfils the need of the user (Blumler and Katz, 1974)[20]. After an extensive literature review of uses and gratifications theory (past and present), Ruggiero (2000) asserts that the emergence of computer-mediated communications has revised the significance of uses and gratifications. He proposes that contemporary and future models must include concepts such as interactivity, demassification, hypertextuality, and asynchroneity[21]. Luo (2002) applied the uses and gratification theory to explore the influences of informativeness, entertainment, and irritation on various online consumer behaviors such as attitude toward the Web, Web usage, and Web satisfaction. The results of a structural equation model reveal that Internet users who perceive the Web as entertaining and informative generally like the Web and show a positive attitude toward the Web[22].

In the context of blogs, there have been some attempts to understand blogging motivations. Nardi et al. (2004) based on ethnographic interviews with bloggers and textual analysis of blog posts, identified five motivations for blogging: documenting the blogger's life, expressing commentary and opinions towards interested issues, releasing emotions, organizing minds through writing, and building community[23]. Using a questionnaire Li (2007) found, after a factor analysis, seven motivations: self-documentation, improving writing, self-expression, medium appeal, information, passing time and socialization. Improving writing was the most important reason, followed by information, medium appeal, self-expression, self-documentation, and socialization. Blogging as a way of passing time was slightly disapproved by respondents[24]. Also, Jones and Alony (2008) identified seven motivations to blog[25]. Similar to $\mathrm{Li}$ (2007)[24] they found need for self-expression and need for documentation. Slightly different from socialization was need for social contact (within existing and new relationships) and academic needs for knowledge and interests (self-documentation). New motivations to blog were need for recognition, need for introspection, and need for artistic activity[25].

From a social psychology point of view Trevino (2005) investigates why college students start to blog, why they stay and why they left[26]. She distinguishes between intrinsic and extrinsic motivations, concluding that some individuals begun a home page to meet new contacts (intrinsic) and others (in large number) do so in order to maintain relationships with family and friends (extrinsic). Power over their blog and the self they choose to reveal or conceal to their audience and gain a "pull" medium when they can post content without directly targeting or imposing upon their audiences to read it are the personal or emotional reasons for keeping a blog. The author not found any clear reason to explain abandonment of the blog[26]. A similar approach was taken by Brady (2006) to investigate the motivations for reading and posting to blogs[27]. Through interviews and an online questionnaire the author concludes that blogging supports a variety of motivations occurring at different levels and changing throughout blogger's lifecycle. He adds that still exist a link between reading and writing blogs and the main motivation to continue to blog is sharing of information (experiences, content and knowledge)[27].

A content analysis of a random blog sample made by Papacharissi (2004) revealed that, an average blog is a self-reflective account that serves the purpose of personal expression and provides the perceived gratification of selffulfillment[28]. Trammel et al. (2006) investigate the motivation of 358 Polish bloggers to test six a priori motivations: self-expression, entertainment, social interaction, passing time, information and professional advancement[29]. The results show that social utility (combination of self- expression and social interaction) was the primary motivation, 
although self-expression as an internal-level motivation was found to outweigh the external-level social interaction motivation. The diversion motivation formed by uniting entertainment and passing time was presented in two thirds of the sample. Information and professional advancement was found residual motivations (10.5\% together)[29].

\section{Methodology}

\subsection{Elements of a Blog}

A wine blog can be defined as using the Internet to engage with wine consumers in a time and manner of their choosing (Olsen and Hermsmeyer, 2008)[30]. Anyone with access to the Internet can set up a free blog by using software such as blogspot.com or blogs.sapo.pt. The templates available made possible to customize the blog page. This page is divided in six main parts: i) the body which is the whole of the page within the browser frame; ii) the outer wrapper that contains all the sections within the blog; iii) the header wrapper is the top section and contains the header, inside of which is the title and the description of the blog; iv) the main column contains the posts section; v) the sidebars are at the side of the posts column, and vi) the footer that lies at the foot of the page. Content is considered to be most important element of blogs (Kargar et al., 2008) and is seen to be directly related to blog success (Safran and Kappe, 2008)[31-32]. Content includes: i) blog posts encompassing a subject title and a body message (that can be short or long in length), a variety of media objects (text, pictures, graphics, multimedia and file formats) and a timestamp to denote time and date; ii) comments are the opportunity that readers have to respond to a blog post; iii) archives permit to store past blog post in an accessible and searchable way; iv) templates allow pages to be built according to author personalization interest (variety of graphical layout, typography and colour schemes). To encourage repeat visits and comments, visitors need to be provided with content (updated blog posts), links, searchable archive, RSS feeds, among other features.

\subsection{Sample and Data Collection}

This study uses two samples to assess the profile and the uses and motivations of Portuguese and international wine bloggers.

The first sample is generated from the list of the top Portuguese wine blogs published in a Portuguese newspaper. This yielded an initial sample of ten blogs. Then, we used a variation of snowball sampling to enlarge the sample (Green, Tull and Albaum, 1988; Malhotra, 1999; Zikmund, 2000) [33-35]. Next, we search for hyperlinks in the blogs identified above to find new Portuguese blogs about wines. This nonprobability sampling technique allows that new blogs will have psychographic characteristics that are more similar to the bloggers referring them than would occur by searching on Internet or using an engine search. The major advantage of snowball sampling is that it substantially increases the likelihood of locating the desired bloggers. It also results in relatively low sampling variance and costs (Malhotra, 1999)[34]. In the end we obtained 35 blogs that we accessed to collect data about Portuguese wine blogs. An extensive content analysis of the 35 blogs was taken from the date of their inception until July 2009. The data collected for analysis include date of started blogging, time of posting and reasons for blogging.

The data selected for analysis of international wine bloggers is from a web-based screening questionnaire managed by www.surveymonkey.com. Questions regarding demographics (country of residence, gender, age, average income in US dollars, education level), blogging activity and traffic (date of start, time of posting), blog features (web statistics, blogging platform(s), licence, language), marketing features (acceptance of samples, advertisement, rating scales) and reasons for blog, were included in the questionnaire. The data were collected in November $6^{\text {th }}, 2008$ and a total of 92 responses were available for further investigation, although some respondents skipped a few questions. The sample is mainly from the United States (two thirds), while Italy and Spain (5 and 4 answers, respectively) are the most represented European countries. The rest of the sample includes more 12 countries, some of them producers of wine (France, Australia and Chile). International wine bloggers were mostly males $(70.7 \%)$ and between 31 and 50 years old (69.6\%). The majority of wine bloggers belong to high income groups: $34.1 \%$ have an annual income between 100.001 and 250.000 US dollars and $56.8 \%$ between 50.000 and 250.000. However, less affluent bloggers exist $(13 \%$ have less than 20.000 US dollars). The bloggers who responded to this questionnaire are well educated having $40.3 \%$ a master degree or $\mathrm{ahD}$ and $34.8 \%$ a bachelor. Most of the respondents belong to the wine industry: more than $50 \%$ are agents in the market (producer, retailer, distributor), while others write about wine (31.4\%).

\subsection{Methods}

A mixed methods approach was used to examine Portuguese and international wine blogs. To examine Portuguese wine bloggers we employed content analysis both quantitative and qualitative: a quantitative content analysis was used to research all the questions, except motivations for blog. To answer this last question a qualitative content analyses was performed based in the first posts which in some cases explain why they begin to blog or the editorial policy of the blog whereas in some cases we can find the main motive to blog. When it is impossible to research the main motivation behind the blog an e-mail was sent to the blogger asking the main reasons for continuing to blog.

The results of a web-based survey taken by Ryan Opaz (from Catavino blog), during 2008, support the investigation of international bloggers. The data were accessed in November $6^{\text {th }}$, through winebrandsblog.com (2008)[36]. To assure the comparability of the data between the two samples some transformations has to be made in some questions: the 
age of blogs (from quantitative to nominal); rating wine (reducing the items of the scale); language (including less mentioned languages in "others" category); web statistics and blogging platform (aggregating options).

\section{Similarities and Differences between Portuguese and International Wine Bloggers}

There are three typical characteristics that identify community: i) a feeling of connection among community's members; ii) the presence of shared rituals and traditions; iii) the idea of a moral responsibility toward the community as a whole and toward theirs members (Muniz and O'Guinn, 2001)[37]. At least, two of the former characteristics are present in the Portuguese wine blog community. A sense of connection is growing between bloggers with the organization of an annual event in Europe and United States (European/North American Wine Bloggers Conference). These conferences provide an open forum to discuss issues regarding the blogging activity (writing, standards, etc.) and wine related themes (tasting and rating wines, etc.). Cross referencing each others on the blog is another example of connection. Needless to say about the rituals associated to wine tasting and drinking. The Portuguese virtual wine community has been consolidating his position in the blogsphere: $37.1 \%$ of bloggers has more than three years and $42.9 \%$ of its members entered during the last two/three years (Table 1). The expression of this reality is the recent (May 31, 2010) inclusion of three Portuguese wine bloggers in the ranking of 100 top wine blogs (http://alawine.com/wine-blog- rankings.html). The international blog community represented in the sample combines those who began their activity more recently (29.4\%) with more experienced bloggers (46.3\%).

Content creation and management is the most important part of the blog activity. Wine posts usually incorporate text (a review of a wine in most cases), links (to original sources), image (a photo of the label or bottle) and video (short films about an event or visit). The posts (past and present) are grouped in a searchable archive. The frequency of posting gives an idea of blog's dynamism: a low frequency rate denotes lost of interest; the opposite is regarded as dynamic. The dynamism of a blog is critical to attract attention, be relevant and maintain up-to-date information about new wines, events and news. The majority of international bloggers are an active community as $71.7 \%$ of them posts more than 5 times per month. The dynamism of Portuguese bloggers is qualitatively different as the number of them is dispersed around the three categories and the sum of the last two (more than 5 times per month) is $62.9 \%$.

A segmentation analysis based on blog traffic has to be made to focus marketing effort. Top bloggers (key influencers) who need to be closely followed to create and maintain a good relationship - subscribe the blog, made pertinent comments on a daily or weekly basis, send press releases, ship wines to taste and rank, invited them to participate in small wine events are some sort of public relations actions that could be taken. Emergent bloggers (below the top) are followed with less attention (monthly basis), but with slightly different marketing effort (for example, invitation to participate in large events, instead of small). New bloggers (new comers) have to be carefully examined (reading the posts and comments) to assess reputation and blog traffic, before further engagement with the blogger. Occasional bloggers have poor traffic and the activity of posting is episodic - marginally marketing effort is needed.

Table 1. Profile of Portuguese and International Bloggers

\begin{tabular}{|c|c|c|c|c|}
\hline \multirow{2}{*}{} & \multicolumn{2}{|c|}{ Portuguese } & \multicolumn{2}{c|}{ International } \\
\cline { 2 - 5 } & $\mathrm{N}$ & $\%$ & $\mathrm{~N}$ & $\%$ \\
\hline Age of blogs & & & & \\
\hline More than 3 years & 13 & 37.1 & 23 & 46.3 \\
\hline Between 2 and 3 years & 15 & 42.9 & 19 & 24.3 \\
\hline Less than 2 years & 7 & 20.0 & 36 & 29.4 \\
\hline Total & 35 & 100 & 78 & 100 \\
\hline Posting & & & & \\
\hline 1 - 4 times per month & 13 & 37.1 & 26 & 28.3 \\
\hline 5 - 7 times per month & 12 & 34.3 & 61 & 66.3 \\
\hline More 7 times per month & 10 & 28.6 & 5 & 5.4 \\
\hline Total & 35 & 100 & 92 & 100 \\
\hline
\end{tabular}

One structural dimension of blogging practices is the blogging software and its underlying architecture (Table 2). Two general types of software exist: blog services and blog script packages: services such as blogger.com offer blog hosting on their servers; blog script packages such as wordpress can be installed, used, and fully controlled on the user's own web server (Schmidt, 2007)[38].

Table 2. Technical Features of Portuguese and International Bloggers

\begin{tabular}{|c|c|c|c|c|}
\hline \multirow{2}{*}{} & \multicolumn{2}{|c|}{ Portuguese } & \multicolumn{2}{c|}{ International } \\
\cline { 2 - 5 } & $\mathrm{N}$ & $\%$ & $\mathrm{~N}$ & $\%$ \\
\hline Blogging platform & & & & \\
\hline Blogspot & 32 & 91.4 & 31 & 33.7 \\
\hline Wordpress.org/com & - & - & 47 & 51.1 \\
\hline Other & 3 & 8.6 & 14 & 15.2 \\
\hline Total & 35 & 100 & 92 & 100 \\
\hline Web statistics $\left.*^{*}\right)$ & & & & \\
\hline Sitemeter & 15 & 39.5 & 8 & 7.0 \\
\hline Google analytics & 1 & 2.6 & 43 & 38.1 \\
\hline Other & 12 & 31.6 & 32 & 28.3 \\
\hline None & 10 & 26.3 & 30 & 26.6 \\
\hline Total & 38 & 100 & 113 & 100 \\
\hline Language (**) & & & & \\
\hline Portuguese & 35 & 70.0 & 6 & 5.9 \\
\hline English & 15 & 30.0 & 83 & 82.2 \\
\hline Other & - & - & 12 & 11.9 \\
\hline Total & 50 & 100 & 101 & 100 \\
\hline License of Content & & & & \\
\hline Creative Commons & 5 & 14.3 & 24 & 26.1 \\
\hline All Rights Reserved & 5 & 14.3 & 14 & 15.2 \\
\hline No license & 25 & 71.4 & 54 & 58.7 \\
\hline Total & 35 & 100 & 92 & 100 \\
\hline So & & & & \\
\hline
\end{tabular}

$(*)$ Some weblogs include more than one web statistics. (**) includes translation. 
Portuguese bloggers concentrate their preferences in the Blogspot platform (91.4\%) which is easy to use and usually allow people to set up a basic blog, but in most cases the user's control over the amount of storage and the design of the blog is limited. Foreigners prefer more diversified platforms such as wordpress $(51.1 \%)$. This platform requires a certain degree of technical expertise for installation and maintenance, but gives greater control over appearance and data.

The use of web statistics is a common means of tracking visitors profile and measure the success of the blog. The analysis of visitors (referrers, recent hits, countries coverage) and traffic statistics such as number of page views, unique visitors, first time visitors and returning visitors are metrics available in software tools. Portuguese bloggers use more Sitemeter (39.5\%), while international bloggers use more Google analytics (38.1\%). However, a large percentage of bloggers in both groups have no counter which seems to be a bad option as the profile of the visitors are not known and measures of blog traffic does not exist. This could be a severe constraint to the future development of the blog.

Blog sites, like other web pages, can fall victim of first impressions phenomenon. This means that even if a web site is highly usable and provides very useful information presented in a logical arrangement, this may fail to impress a user whose first impression of the site was negative (Blair and Level, 2008)[39]. English is almost a universal language in the international blogosphere $(82.2 \%)$. Nevertheless, searching the Portuguese blogs is not always easy as only $30.0 \%$ of blogs possess translation to English language and a limited number publish their content in English.

Licensing the online content of the blog assures that when visitors copy and distribute information they have to give credit to the publisher. Authorship is the focal point of this feature as citations can raise the number of new visitors, improve blog traffic and increase personal awareness in the virtual community. There is a large number of bloggers (Portuguese and foreigner) without copyright protection ( $71.4 \%$ and $58.7 \%$, respectively). Creative Commons licensing is cited more frequently by foreigners as a tool to letting others know exactly what they can and can't do with the content of the blog.

Some important technical features of blogs are useful for marketing purposes. In this study the selected features are wine reviews, samples' acceptance and advertising adoption (Table 3). In the wine business taste and rating wines is one of the most important marketing features the blogger can offer to consumers and wine firms. Thach (2010) conducting a content analysis of 222 English language wine blogs found that there are 9 major categories of wine blogs, with the most common being reviews and ratings of wines by consumer bloggers[40]. Most of the Portuguese wine bloggers (65.7\%) taste and rating wines. The same is not true to international bloggers as $66.3 \%$ of them don't rate wines.

Scales used vary between 1-100 points/star/asterix and $5 / 10 / 20$ points or thumbs up and down (both samples prefer a $10 / 20$ points scale). In virtual communities as the wine blogs, a positive review or recommendation can be disseminated rapidly through eWOM. Therefore, wine reviews with rating are a very powerful tool to marketing a wine via Internet in an effective and costless way.

Table 3. Marketing Features of Portuguese and International Bloggers

\begin{tabular}{|c|c|c|c|c|}
\hline \multirow{2}{*}{} & \multicolumn{2}{|c|}{ Portuguese } & \multicolumn{2}{c|}{ International } \\
\cline { 2 - 5 } & $\mathrm{N}$ & $\%$ & $\mathrm{~N}$ & $\%$ \\
\hline System of rating wines & & & & \\
\hline 100 points/star/asterix & 4 & 11.4 & 8 & 8.7 \\
\hline 5/10/20, thumbs up/down & 19 & 54.3 & 23 & 25.0 \\
\hline Don't rate wines & 12 & 34.3 & 61 & 66.3 \\
\hline Total & 35 & 100 & 92 & 100 \\
\hline Acceptance of wine samples & & & & \\
\hline Yes & 8 & 22.9 & 63 & 68.5 \\
\hline No & 27 & 77.1 & 29 & 31.5 \\
\hline Total & 35 & 100 & 92 & 100 \\
\hline Acceptance of advertising & & & & \\
\hline Yes & 13 & 37.1 & 39 & 42.4 \\
\hline No & 22 & 62.9 & 53 & 57.6 \\
\hline Total & 35 & 100 & 92 & 100 \\
\hline
\end{tabular}

The acceptance of samples of wine reduces the independence of who taste and rate the wine. Perhaps this is the reason why so many Portuguese bloggers (77.1\%) rejected samples or at least don't encourage firms to send samples. The positioning of foreign bloggers is totally different as a large percentage of foreign bloggers accept samples $(68.5 \%)$. The reference in the evaluation note that the sample has been sent by the producer can attenuate the problem of credibility perceived by the consumer. The acceptance of samples could be beneficial for producers of wines as a positive rating on various blogs could generate friendly eWOM which is very important for less known wines/brands; online shops that could increase the sales of the rated wine/brand; and bloggers that could use this marketing tool to increase blog traffic.

The mechanical characteristics of the blog allow the inclusion of ads with text, colour, image, sound and video. The exposure of blog visitors to ad formats such as banners and text ads is voluntary when browsing activity is not interrupted. Intrusive ad formats such as pop-ups interrupt browsing activity and demand immediate response from the visitor. The advertising put in the right or left side of the blog page is a way to increase revenue, but both samples indicate that for the majority of Portuguese and international wine bloggers (62.9\% and $57.6 \%$, respectively) accepting advertising is not an option. Research shows that exposure of blog visitors to banner advertising can lead to brand recall, ad recognition and brand attitude (Chartterjee, 2008)[41]. Xu et al. (2009) reported positive effects on attitude, intention to use and purchase intention[42]. However, the role of advertising is somewhat a double-edged sword: on the one hand, only the more influential bloggers can attract advertising as the buyers search traffic, demographics and reach; on the other hand, the abuse of advertising on the blog can deter returning visitors, as can be considered an irritating factor for people that visit the page more frequently.

In order to examine the rationale behind wine blogging 
(Table 4) we considered four main motivations. The first three denotes motivations already pointed out by empirical research mentioned above: i) diversion motivation (grouping entertainment and passing time) as the answer to "I blog as a hobby"; ii) professional advancement as the answer to "I blog to help promote myself in other related work"; iii) information as the answer to "I blog to keep track of wine I like". The fourth motivation was put forward as answers to "I blog for a living" and "I am working towards using this as my primary source of income" indicate financial motivation.

Table 4. Motivations for Wine Blogging

\begin{tabular}{|c|c|c|c|c|}
\hline & \multicolumn{2}{|c|}{ Portuguese } & \multicolumn{2}{c|}{ International } \\
\cline { 2 - 5 } & $\mathrm{N}$ & $\%$ & $\mathrm{~N}$ & $\%$ \\
\hline I blog for a living & - & - & 2 & 2.2 \\
\hline I blog as a hobby & 24 & 65.7 & 4 & 4.4 \\
\hline $\begin{array}{c}\text { I am working towards using this as } \\
\text { my primary source of income }\end{array}$ & - & - & 12 & 13.0 \\
\hline $\begin{array}{c}\text { I blog to help promote myself in } \\
\text { other wine related work }\end{array}$ & 6 & 17.2 & 57 & 61.9 \\
\hline I blog to keep track of wine I like & 4 & 11.4 & 13 & 14.1 \\
\hline Skipped questions & 2 & 5.7 & 4 & 4.4 \\
\hline Total & 35 & 100 & 92 & 100 \\
\hline
\end{tabular}

Main motivation for Portuguese wine bloggers is diversion revealing that most of the blogging activity is maintain as a hobby. In the opposite side are international bloggers that blog for professional advancement. Contrary to generalists polish bloggers where this reason was residual, there seems to be that wine blogging activity is very specific as can leads to personal awareness, increased reputation and authority. Some of them may envisage opinion leader status such as Jamie Goode, a British wine writer and blogger.

Professional advancement is the main motivation for international blogers, as they want to be famous in the blogosphere to acquire a certain status and then extend this personal asset to others wine related activities. Interestingly, some of the international bloggers $(15.2 \%)$ are guided for financial reasons as they are living or are trying to live exclusively of wine blogging. This motivation was not mentioned by previous empirical research and is similar to Portuguese bloggers behaviour. Further research is needed to identify the activities that generate revenue and explore the implications for bloggers.

A series of univariate ANOVA was used to test the differences between Portuguese and international bloggers practices. Table 5 shows that practices of rating wine between Portuguese and international boggers differs significantly, $\mathrm{F}(1,126)=9.38, \mathrm{p}<0.01$. As we see before, Portuguese bloggers tends to rate wines more often than the international bloggers. The acceptance of samples of wine predominantly by international bloggers is another significant difference, $\mathrm{F}(1,126)=25.34, \mathrm{p}<0.01$. The analysis also shows a significant difference in the inception of the blog, $\mathrm{F}$ $(1,112)=4.04, p<0.05$, as international community seems to accommodate both younger bloggers and more experienced ones.

With regard to blogging motivations the difference is significant, $F(1,126)=5.74, p<0.05$. The most obvious explanation rests in financial motivation which did not exist in the Portuguese community and the professional advancement motivation which is less important too.

Similar practices between Portuguese and international bloggers appear to exist as no support was found to differences in the frequency of posts, presence of advertising, statistical tools to measure blog traffic and the licence of blog content.

Table 5. ANOVA Results Differences across Portuguese and International Bloggers

\begin{tabular}{|c|c|c|c|c|}
\hline $\begin{array}{c}\text { Variables } \\
\text { (Scales) }\end{array}$ & $\begin{array}{c}\text { Portuguese } \\
(\text { Mean })\end{array}$ & $\begin{array}{c}\text { International } \\
(\text { Mean })\end{array}$ & $\mathrm{F}$ & Significance \\
\hline Age $(1,3)$ & 2.17 & 1.83 & 4.04 & $p<0.05$ \\
\hline Posts $(1,3)$ & 1.91 & 1.77 & 1.31 & n. s. \\
\hline Rating $(0,1)$ & 0.63 & 0.34 & 9.38 & $p<0.01$ \\
\hline Samples $(0,1)$ & 0.23 & 0.68 & 25.34 & $p<0.01$ \\
\hline Advertising $(0,1)$ & 0.4 & 0.42 & 0.05 & n. s. \\
\hline Statistics $(0,1)$ & 0.74 & 0.44 & 0.56 & n. s. \\
\hline Licence $(0,1)$ & 0.29 & 0.41 & 1.74 & n. s. \\
\hline Motivation $(0,3)$ & 1.4 & 1.79 & 5.74 & $p<0.05$ \\
\hline
\end{tabular}

\section{Conclusions}

Portuguese and international wine bloggers appears to be a niche wine consumption community, relatively young and dynamic. As a new form of communication blogs inherit the main characteristics of computer-mediated communication while exhibiting some new features by presenting the combination of online self representation, community building, and interpersonal communication (Li, 2007)[24]. In line with this assumption, motivation for blogging indicates that diversion is an important part of the activities developed by Portuguese bloggers, while self promotion (representation) is searched by international bloggers who want to acquire status. The organisation of international conferences (European and American) suggests a sense of connection among members around wine and related issues. The rituals associated to wine tasting and drinking denotes they shared the same interests. Collective actions against accuses coming from outside indicates moral responsibility. Portuguese and international wine bloggers can be considered a specific consumption community as they fulfil, at least, two main characteristics: connection among members and shared rituals and traditions. The participation of marketers in virtual communities of consumption as members can improve the knowledge on how decisions on product evaluation are made, examine different product's usages, identify dominant attitudes towards products or brands and understand consumer preferences and choices.

Posting a favourable evaluation in a dynamic and influential wine blog can generate positive eWOM which can affect consumer purchasing behaviour. Research suggests that positive reviews lead to an increase in relative sales (Chevalier and Mayzlin, 2006)[19]. Blogs allow new opportunities to find opinion leaders online. General search 
engines such as technorati or alawine are all venues to approach influencers (three Portuguese wine bloggers are identified in the ranking of 100 top wine blogs of alawine). The identification by wine agents (producers, importers, etc.) of the most influential bloggers can be useful to target specific actions of direct marketing. One obvious action is send wine as a sample to an influential blogger expecting a favourable review in their blog. Another could be an invitation to visit the winery and report wine tasting. Finally, a close attention is needed to the posts published on the blog: reading and comment the posts if the subject affects the firm, explain some misunderstandings regarding the wine business or contradict wrong information is only examples of follow-up actions.

Reading and replying the comments helps the blogger to interact and have some feedback from the visitors. This interactive element is important because allows the reader to submit their opinion and express disagreement about different sort of wine related subjects. This interactivity tries to increase reader involvement and approximates the blog of a two-way communication medium.

Another important feature of the blog is the possibility of including web statistics which contains relevant data that permit to know the audience (demographics, geographic coverage, exposure, etc.). This enables media buyers to target specific audiences as wine bloggers offers selectivity. Additionally, the qualitative data that can be collected on wine blogs (posts and comments about a specific wine) are an important primary source for marketing research.

Contrary to traditional media (for example TV or Radio) blogs demand active participation from bloggers in order to produce content. Thus, blogging suggests a consciousness of the expected gratifications and subjective intentionality to create content. The frequency of posting denotes a rationality of publish or perish as most of them post more than 5 times per month. A balance between relevance of posting (utility of the information for the users), necessity of being online (maintaining and attract attention) and disposable time of the blogger (how many hours) has to be made. The increasing number of international bloggers that wants to be professionals is a good indicator of the time spent in this activity.

Wine firms should recognize the growing importance of blogs and their use as a marketing tool. Different actions can be taken by the wine firm: i) adopt a corporate blog that provide strong control over message; ii) sponsor a blog that assures strong coverage of all the activities of the wine firm; iii) insert a banner in a blog which permits to control the form and content of the message and attract attention to the online shop or wine firm's site.

This research may help the Portuguese and international bloggers to enlarge their knowledge regarding blogging practices, uses and motivations. Significantly differences have been found in practices (age of the blogs), uses (rating wine and accepting wine samples), and motivations (mostly financial reasons for international bloggers).

A strong limitation of the study has to deal with the international sample: i) a bias toward the US bloggers could restrain the results extrapolation to the whole international blog community; ii) the same applies to the sample size regarding some countries representation. Another major constraint is the dual methodological approach that has to be taken in order to assess the comparability between Portuguese and international motivations (content analysis versus survey).

Future studies should investigate the effectiveness of blogs for marketing purposes using experiments: i) to evaluate the impact of specific direct marketing or public relations actions on bloggers posting activities and attitudes; ii) to evaluate the influence of top bloggers activity on consumers' buying behaviour towards wine acquisition choices (brand, region-of-origin, variety, etc.). Also, qualitative studies were needed in order to have a deep insight of: i) bloggers' personality traits and typologies; ii) propensity factors (internal or external) to blog; iii) main reasons and motivations behind bloggers activity.

\section{ACKNOWLEDGEMENTS}

The author acknowledges all the support of the Economic Policies Research Unit (NIPE), School of Economics and Management (EEG), Minho University, Portugal.

\section{REFERENCES}

[1] ITU (International Telecommunication Union), 2011, Measuring the information Society: the ICT development index, Geneva, Switzerland.

[2] Weber, Larry, 2009, Marketing the social web, John Wiley \& Sons, Hoboken, New Jersey.

[3] Wright, Jeremy, 2006, Blog Marketing, McGraw-Hill, New York.

[4] Technorati, 2008, State of the blogosphere.[Online]. Available:

[5] http://technorati.com/blogging/state-of-the-blogosphere/, retrieved 14/07/09.

[6] Universal McCann, 2008, Wave.3.[Online]. Available: http://www.universalmccann/Assets/wave_3 200804030937 50.pdf, retrieved 14/07/09.

[7] Kozinets, R. V. et al., 2010, "Networked narratives: understanding word-of-mouth marketing in online communities", Journal of Marketing, 74(2), 71-89.

[8] Trusov, M. et al., 2009, "Effects of word-of-mouth versus traditional marketing: findings from an Internet social networking site", Journal of Marketing, 73(5), 90-102.

[9] Woerndl, M. et al., 2008, "Internet-induced marketing techniques: critical factors in viral marketing campaigns", International Journal of Business Science and Applied Management, 3 (1), 33-45.

[10] Thompson, S. A. and Sinha, R. K., 2008, "Brand communities 
and new product adoption: the influence and limits of oppositional loyalty", Journal of Marketing, 72(6), 65-80.

[11] Menzie, K. A. and Keyton, J., 2007, "Building public relations through blogging: relationship marketing and social presence perspectives", Paper presented at the Annual Meeting of the NCA $93^{\text {rd }}$ Annual Convention, TBA, Chicago.

[12] Berger, F., 1987, "Public relations aspects of marketing", in Buell, V. P. (Ed.), Handbook of Modern Marketing, McGraw-Hill International Editions, London, Chapter 86, pp. $86.1-86.12$

[13] Senecal, S. and Nantel, J., 2004, "The influence of online product recommendations on consumers' online choices", Journal of Retailing, 80,159-169.

[14] Karrh, J. A. et al., 2003, "Practitioners' evolving views on product placement effectiveness", Journal of Advertising Research, 43(2), 138-144.

[15] Xia, L. and Bechwati, N. N., 2008, "Word of mouse: the role of cognitive personalization in online consumer reviews", Journal of Interactive Advertising, 9(1), 3-13.

[16] Xiaofen, J. and Yiling, Z., 2009, "The impacts of online word-of-mouth on consumer's buing intention on apparel: an empirical study", Proceedings of the 2009 International Symposium on Web Information Systems and Applications (WISA’ 09), May 22-24, Nanchang, P. R. China.

[17] Ives, B. and Watlington, A., 2005, "Using blogs for personal KM and community building", Knowledge Management Review, 8 (3), 12-15.

[18] Jang, H. et al., 2008, "The influence of on-line brand community characteristics on community commitment and brand loyalty", International Journal of Electronic Commerce, 12(3), $57-80$.

[19] Vecchio, P. D. et al., 2009, "Brand-based bloggers' communities: driving the boundaries of the customer satisfaction in the blogosphere", 8th Internacional Conference Marketing Trends, 15-17 January, Paris.

[20] Chevalier, J. A and Mayzlin, D. (2006), "The effect of word-of-mouth on sales: online book reviews", Journal of Marketing Research, 43(3), 345-354.

[21] Blumler, J. G. and Katz, E., 1974, The uses of mass communication: current perspectives on gratifications research, Sage, Beverly Hills, CA.

[22] Ruggiero, T., 2000, "Uses and gratifications theory in the $21^{\text {st }}$ century", Mass Communications \& Society, 3(1), 3-37.

[23] Luo, X., 2002, "Uses and gratification theory and e-consumer behaviours: a structural equation modelling study", Journal of Interactive Advertising, 2(2), 34-41.

[24] Nardi, B. A. et al., 2004, "Why we blog", Communications of the ACM, 47(12), 41-46.

[25] Li, D., 2007, "Why do you blog: a users-and-gratifications inquiry into bloggers' motivations", Paper presented at the Annual Meeting of The International Communication Association, TBA, San Francisco, CA, May 24.

[26] Jones, M. and Alony, I., 2008, "Blogs: the new source of data analysis", Issues in Informing Science and Information
Technology, 5.

[27] Trevino, E. M., 2005, "Blogger motivations: power, pull and positive feedback", Paper presented at 6th Annual AoIR Conference, Chicago, October.

[28] Brady, M., 2006, "Blogs: motivations behind the phenomenon", Paper presented at the Information Communication Society Conference, University of York, UK, September.

[29] Papacharissi, Z., 2004, "The blogger revolution? Audience as media producers", Paper presented in the Communication and Technology Division, International Communication Association, New Orleans, LA.

[30] Trammel, K. D. et al., 2006, "Republic of blog: examining Polish bloggers through content analysis", Journal of Computer-Mediated Communication, 11(3).

[31] Olsen, J. and Hermsmeyer, J., 2008, "Direct wine sales and wine 2.0", in Tach, L. and Matz, T. (Eds), Wine: a global business, $2^{\text {nd }}$ Edition, Miranda Press, New York.

[32] Kargar, M. J. et al., 2008, "Formulating priory of information quality criteria on the blog", World Applied Sciences Journal, 4(4), 586-593.

[33] Safran, C. and Kappe, F., 2008, "Success factors in a weblog community", Journal of Universal Computer Science, 14(4), 546-556.

[34] Green, P.E., Tull, D.S. and Albaum, G., 1988, Research for marketing decisions, $5^{\text {th }}$ edition, Prentice Hall International Editions, New Jersey.

[35] Malhotra, N. K., 1999, Market research: na applied orientation, Third Edition, Prentice Hall, New Jersey.

[36] Zikmund, W. G., 2000, Exploring marketing research, 7h edition, Dryden Press, Orlando.

[37] Winebrandsblog.com, 2008, "Results of a survey on wine bloggers", post of November 4th, link the results. (http://www.winebrandsblog.com/2008/11/results-of-surveyon-wine-bloggers.html, accessed 06/11/2008).

[38] Muniz, A. M. Jr and O'Guinn, T. C., 2001, "Brand community”, Journal of Consumer Research, 27(4), 412-432.

[39] Schmidt, J., 2007, "Blogging practices: an analytical framework", Journal of Computer-Mediated Communication, 12 (4).

[40] Blair, J. and Level, A. V., 2008, "Creating and evaluating a subject-based blog: planning, implementation, and assessment", Reference Services Review, 36(2), 156-166.

[41] Thach, L., 2010, "Wine blogs: expressing diverse wine opinions in a new realm of online wine relationship marketing", $5^{\text {th }}$ International Academy of Wine Business Research Conference, 8 - 10 February, Auckland, New Zealand.

[42] Chatterjee, P., 2008, "Are unclicked ads wasted? Enduring effects of banner and pop-up ad exposures on brand memory and attitudes", Journal of Electronic Commerce Research, 9 (1), 51-61.

[43] Xu, H. et al., 2009, "Perceived effectiveness of text vs. multimedia Location-Based Advertising messaging", International Journal of Mobile Communications, 7 (2), 154-177. 